\title{
Contrasting cellular uptake pathways for chlorido and iodido iminopyridine ruthenium arene anticancer complexes $\dagger$
}

\author{
Isolda Romero-Canelón, Ana M. Pizarro, Abraha Habtemariam and \\ Peter J. Sadler*
}

Received 25th September 2012, Accepted 30th October 2012

DOI: $10.1039 / \mathrm{c} 2 \mathrm{mt} 20189 \mathrm{e}$

The pathways involved in cellular uptake and accumulation of iminopyridine complexes of general formula $\left[\mathrm{Ru}\left(\eta^{6}-p\right.\right.$-cymene $)\left(N, N\right.$-dimethyl- $N^{\prime}-[(E)$-pyridine-2-ylmethylidene]benzene1,4-diamine) $\mathrm{X}_{\mathrm{P}} \mathrm{PF}_{6}$ bearing two different halido ligands $\mathrm{X}=\mathrm{Cl}$ or $\mathrm{I}$, have been explored. The ratio of passive/active cellular accumulation of Ru in A2780 human ovarian cancer cells is compared and contrasted with cisplatin. Also, saturation of cellular uptake, time-dependence of cellular influx/efflux equilibria, together with endocytotic pathways such as caveolae and facilitated diffusion are investigated and discussed. Temperature dependence studies of Ru accumulation in the A2780 cells show that in contrast to cisplatin (CDDP) and chlorido complex $\mathbf{1}$, which are taken up largely through active transport, the iodido complex 2 enters cells via passive transport. The cellular efflux of Ru is slow $(c a .25 \%$ retained after $72 \mathrm{~h})$ and is partially inhibited by verapamil, implicating the P-gp protein in the efflux mechanism. Ouabain inhibition experiments suggest that the cellular uptake of these ruthenium complexes relies at least in part on facilitated diffusion, and in particular is dependent on the membrane potential. In addition the finding that depletion of cellular ATP with antimycin A had little effect on cellular Ru accumulation from iodido complex $\mathbf{2}$ is consistent with passive diffusion. In contrast, ATP depletion caused a major increase in cellular accumulation of ruthenium from chlorido complex $\mathbf{1}$.

\section{Introduction}

Ruthenium arene anticancer complexes are being widely studied as potential alternatives to platinum chemotherapeutics, ${ }^{1-9}$ especially because acquired resistance to platinum-based drugs represents a major clinical drawback for compounds such as cisplatin $(\mathrm{CDDP})^{10,11}$ and oxaliplatin (OXA). ${ }^{12,13}$ This type of resistance usually develops as a consequence of impaired cellular accumulation that can be caused by lower cellular uptake or increased cellular efflux. ${ }^{10,14,15}$ There is much current interest in understanding the mechanisms of cellular uptake for CDDP and platinum accumulation in cells, including the role of the copper transport protein CTR $1 .{ }^{16-18}$ However, much less is known regarding the mechanisms involved in the cellular accumulation of ruthenium anti-cancer drugs. Deeper understanding of these pathways could contribute to rational design and further improvement of such complexes. In general, although not always, cell accumulation of a drug is directly related to potency. In the work reported here, the cellular uptake and

Department of Chemistry, University of Warwick,

CoventryCV47AL,UK.E-mail:p.j.sadler@warwick.ac.uk;

Fax: + 44 (0) 247652 3819; Tel: + 44 (0) 2476523818

$\dagger$ Electronic supplementary information (ESI) available. See DOI: $10.1039 / \mathrm{c} 2 \mathrm{mt} 20189 \mathrm{e}$ metal accumulation mechanisms are compared for chlorido and iodido iminopyridine ruthenium(II) arene anticancer complexes, including time-, concentration- and temperature-dependence as well as extent of metal efflux. The effects on metal accumulation investigated include (a) the role of the $\mathrm{Na}^{+} / \mathrm{K}^{+}$pump, as a facilitated diffusion endocytosis pathway, (b) membrane disruption by amphotericin B as a model for protein-mediated transport, (c) the role of the caveolae endocytosis pathway, as well as (d) the role of the copper uptake protein CTR1, and (e) ATP depletion. We have also investigated P-gp glycoproteinmediated efflux. For these studies, two isostructural complexes $1\left[\mathrm{Ru}(p\right.$-cym) (ImpyNMe $) \mathrm{Cl}_{3} \mathrm{PF}_{6}$ and $2[\mathrm{Ru}(p$-cym)(Impy$\left.\left.\mathrm{NMe}_{2}\right) \mathrm{I}\right] \mathrm{PF}_{6}$ which only differ in their monodentate halido ligand were selected so that the specific effect on the cellular uptake processes of complexes bearing either a chloride or iodide as a monodentate ligand could be studied.

\section{Experimental}

\section{Materials}

The dimer $\left[\mathrm{Ru}\left(\eta^{6}-p\right.\right.$-cymene $\left.) \mathrm{Cl}_{2}\right] \mathrm{Cl}_{2},{ }^{19,20}$ and complexes $\mathbf{1}$ and 2 (Fig. 1) were synthesised and characterised as reported. ${ }^{21}$ Verapamil hydrochloride $(\geq 99.0 \%)$, ouabain octahydrate ( $\geq 95 \%$ ), antimycin A from Streptomyces sp., amphotericin 


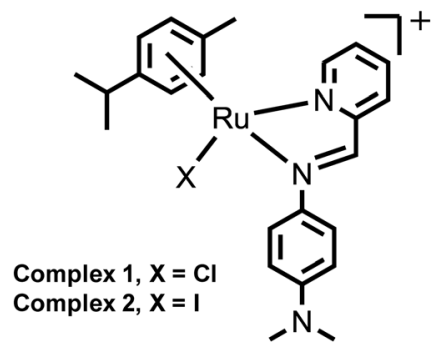

Fig. 1 Structures of complexes $\mathbf{1}$ and $\mathbf{2}$.

B from Streptomyces sp., methyl $\beta$-cyclodextrin and copper(II) chloride dihydrate $(\geq 99.0 \%$ ) were purchased from SigmaAldrich.

\section{Cell culture}

The A2780 ovarian cancer cell line was obtained from the ECACC (European Collection of Animal Cell Culture, Salisbury, UK). The cells were maintained in RPMI 1640 medium which was supplemented with $10 \%$ fetal calf serum, $1 \%$ L-glutamine and $1 \%$ penicillin/streptomycin. All cells were grown at $310 \mathrm{~K}$ in an humidified atmosphere containing $5 \%$ $\mathrm{CO}_{2}$.

\section{In vitro growth inhibition assay}

The antiproliferative activity of complexes 1, 2 and CDDP was determined in the A2780 ovarian cancer cell line. Briefly, 96-well plates were used to seed 5000 cells per well; they were left to pre-incubate in drug-free medium at $310 \mathrm{~K}$ for $48 \mathrm{~h}$ before adding various concentrations of the compounds to be tested. A drug exposure period of $24 \mathrm{~h}$ was allowed. After this, the supernatants were removed by suction and each well was washed with PBS. A further $72 \mathrm{~h}$ was allowed for the cells to recover in drug-free medium at $310 \mathrm{~K}$. The SRB assay was used to determine cell viability. This assay, first developed by Skeham et al. in $1990,{ }^{22}$ is based on the ability of the sulforhodamine B to bind electrostatically to basic amino acid residues of proteins from fixed cells. Absorbance measurements of solubilised dye allow the determination of the amount of viable treated cells against an untreated control. These measurements were carried on a BioRad iMark microplate reader using a $470 \mathrm{~nm}$ filter. $\mathrm{IC}_{50}$ values, as the concentration which cause $50 \%$ inhibition of cell growth, were determined as duplicates of triplicates in two independent sets of experiments, and their standard deviations calculated.

\section{Metal accumulation in cancer cells}

Metal accumulation studies for complexes 1, 2 and CDDP were conducted on the A2780 ovarian carcinoma cell line. Briefly, $4 \times 10^{6}$ cells were seeded on a Petri dish; after $24 \mathrm{~h}$ of pre-incubation time in drug-free medium, at $310 \mathrm{~K}$ in a $5 \%$ $\mathrm{CO}_{2}$ humidified atmosphere, the test complexes were added to give final concentrations equal to $\mathrm{IC}_{50} / 3$ and then allowed a further $24 \mathrm{~h}$ of drug exposure under similar conditions. After this time, cells were treated with trypsin, counted, and cell pellets were collected. Each pellet was digested overnight in concentrated nitric acid $(73 \%)$ at $353 \mathrm{~K}$; the resulting solutions were diluted to $5 \% \mathrm{v} / \mathrm{v} \mathrm{HNO}_{3}$ using doubly deionised water, and the amount of ruthenium/platinum taken up by the cells was determined by ICP-MS, using an Agilent Technologies 7500 series instrument. The solvent used for all ICP-MS experiments was double deionised water (DDW) with $5 \%$ $\mathrm{HNO}_{3}$. Metal standards $(\mathrm{Ru} / \mathrm{Pt})$ were freshly prepared before each experiment. The concentrations used for the calibration curve were in all cases $0,5,10,50,200,500,1 \times 10^{3}, 5 \times 10^{3}$, $10 \times 10^{3}, 50 \times 10^{3}, 200 \times 10^{3} \mathrm{ppt}$. The isotopes detected were ${ }^{101} \mathrm{Ru}$ and ${ }^{195} \mathrm{Pt}$; readings were made in duplicate (He gas and no-gas mode). These experiments did not include any cell recovery time in drug-free medium. They were all carried out in triplicate in two set of independent experiments and the standard deviations were calculated. The statistical significance of all cellular accumulation values was determined as $P<0.05$. Results are compared to the corresponding data for CDDP.

Further metal accumulation experiments were carried out as described above including the following experimental variations. In all cases, $4 \times 10^{6}$ A2780 cells were seeded in Petri dishes, the pre-incubation time in drug-free medium at $310 \mathrm{~K}$ was $24 \mathrm{~h}$, and the drug concentrations used were equipotent and equal to $\mathrm{IC}_{50} / 3(\mathrm{CDDP}=0.4 \mu \mathrm{M}$, complex $\mathbf{1}=5 \mu \mathrm{M}$ and complex $\mathbf{2}=$ $1 \mu \mathrm{M})$ unless otherwise stated.

Time dependence. These experiments involved variable drug exposure time and no recovery time in drug-free medium. The chosen time points for drug exposure were: 1, 4, 8, 24, 48, 72 and $96 \mathrm{~h}$.

Temperature dependence. Experiments were carried out using $8 \mathrm{~h}$ of drug exposure with no recovery time in drug-free medium. The chosen temperatures for incubation with the drugs were: 277,293 and $310 \mathrm{~K}$.

Concentration dependence. These experiments used $24 \mathrm{~h}$ of drug exposure at $310 \mathrm{~K}$ and no recovery time in drug-free medium. The chosen equipotent drug concentrations were: $0.16,0.33,1.6,3.2,6.4$ and $9.6 \times \mathrm{IC}_{50}$.

Extent of efflux. In these experiments, drugs were removed after $24 \mathrm{~h}$ of exposure at $310 \mathrm{~K}$ and fresh drug-free medium was added to the cells in the Petri dishes. Cells were incubated again in drug-free medium for 24,48 and $72 \mathrm{~h}$ to allow for recovery before being treated with trypsin to collect the cell pellets.

Inhibition of efflux. Experiments were done using $24 \mathrm{~h}$ of drug exposure time at $310 \mathrm{~K}$ and $24 \mathrm{~h}$ of recovery time using drug-free fresh medium with $5 \mu \mathrm{M}, 10 \mu \mathrm{M}$ or $20 \mu \mathrm{M}$ of verapamil.

Role of $\mathrm{Na}^{+} / \mathrm{K}^{+}$pump in cellular metal accumulation, as a facilitated diffusion endocytosis pathway. These experiments involved $24 \mathrm{~h}$ of drug exposure at $310 \mathrm{~K}$, co-administration of the drug with $5,10,20 \mu \mathrm{M}, 0.1$ or $0.2 \mathrm{mM}$ of ouabain. No recovery time in drug-free medium was allowed.

Role of CTR1 in cellular metal accumulation. Experiments were carried out using $24 \mathrm{~h}$ of drug exposure time at $310 \mathrm{~K}$ and co-administration of the drug with $10,20,40 \mu \mathrm{M}, 0.1$ or $0.2 \mathrm{mM}$ of copper(II) chloride. No recovery time in drug-free medium was allowed. 
Effect of ATP depletion on cellular metal accumulation. Experiments were performed using $24 \mathrm{~h}$ of drug exposure time at $310 \mathrm{~K}$ and co-administration of the drug with 5 and $20 \mu \mathrm{M}$ of antimycin A. No recovery time in drug-free medium was allowed.

Membrane disruption by amphotericin B as a model for protein-mediated uptake. These experiments were carried out using $24 \mathrm{~h}$ of drug exposure and co-administration of the drug with $1,5,10$ or $20 \mu \mathrm{M}$ of amphotericin B. No recovery time in drug-free medium was allowed.

The role of caveolae endocytosis pathway in metal accumulation. These experiments involved $24 \mathrm{~h}$ of drug exposure and co-administration of the drug with $10,20 \mu \mathrm{M}, 0.5$ or $1 \mathrm{mM}$ of methyl $\beta$-cyclodextrin. No recovery time in drug-free medium was allowed.

\section{Results}

\section{Synthesis and characterization}

Ruthenium arene complexes 1 [Ru(p-cym)(ImpyNMe $\left.\mathrm{N}_{2}\right) \mathrm{Cl}_{3} \mathrm{PF}_{6}$ and $2[\mathrm{Ru}(p$-cym $)(\operatorname{ImpyNMe} 2) \mathrm{I}] \mathrm{PF}_{6}$ were prepared via their respective $\mathrm{I}-$ or $\mathrm{Cl}$-bridged dimers, as previously reported and were characterized by standard methods. ${ }^{21}$

\section{In vitro growth inhibition assay}

The antiproliferative activity of complexes $\mathbf{1}$ and $\mathbf{2}$ towards A2780 human ovarian cancer cells was determined using the SRB assay. The iodido complex 2 shows similar potency to CDDP and is ca. $5 \times$ more active than the chlorido complex 1 (Table 1).

\section{Metal accumulation and distribution in cancer cells}

Total cellular accumulation of ruthenium from complexes $\mathbf{1}$ and $\mathbf{2}$ was determined for A2780 ovarian cells using equipotent concentrations at $\mathrm{IC}_{50} / 3$. Ruthenium accumulation after $24 \mathrm{~h}$ of drug exposure at $310 \mathrm{~K}$ in a $5 \% \mathrm{CO}_{2}$ humidified atmosphere was lower for complex $\mathbf{1}(7.5 \pm 0.5 \mathrm{ng}$ Ru per million cells) than for complex 2 (11.9 $\pm 0.8 \mathrm{ng}$ per million cells). In contrast the accumulation of $\mathrm{Pt}$ from CDDP at an equivalent dose $\left(\mathrm{IC}_{50} / 3\right)$ is $c a .90 \times$ less on a molar basis (Table 1 ).

Time dependence. The accumulation of ruthenium for complexes $\mathbf{1}$ and $\mathbf{2}$ in A2780 cells at $310 \mathrm{~K}$ was determined at different time points using equipotent concentrations at $\mathrm{IC}_{50} / 3$. The general trend shows that the maximum cellular accumulation of $\mathrm{Ru}$ (and $\mathrm{Pt}$

Table 1 Antiproliferative activity of complexes 1, 2 and CDDP in the A2780 ovarian cancer cell line

\begin{tabular}{lcc}
\hline Compound & $\mathrm{IC}_{50}{ }^{a}(\mu \mathrm{M})$ & $\begin{array}{c}\text { Cellular accumulation } \\
\left(\mathrm{ng} \mathrm{Ru} / \mathrm{Pt} \times 10^{6} \text { cells }\right)\end{array}$ \\
\hline $\mathbf{1}$ & $16.2 \pm 0.9$ & $7.5 \pm 0.5$ \\
$\mathbf{2}$ & $3.0 \pm 0.2$ & $11.9 \pm 0.8$ \\
$\mathrm{CDDP}$ & $1.2 \pm 0.2$ & $0.25 \pm 0.03$ \\
${ }^{a} \mathrm{IC}_{50}$ is expressed as the concentration of each complex which causes \\
$50 \%$ cancer cell growth inhibition. ${ }^{b}$ Total accumulation of $\mathrm{Ru} / \mathrm{Pt}$ in \\
A2780 cells for complexes $\mathbf{1}, \mathbf{2}$ and CDDP after 24 h of drug exposure \\
at $310 \mathrm{~K}$ with no recovery time. Equipotent concentrations used were \\
$\mathbf{1}=5 \mu \mathrm{M}, \mathbf{2}=1 \mu \mathrm{M}$ and CDDP $=0.4 \mu \mathrm{M}$.
\end{tabular}

A

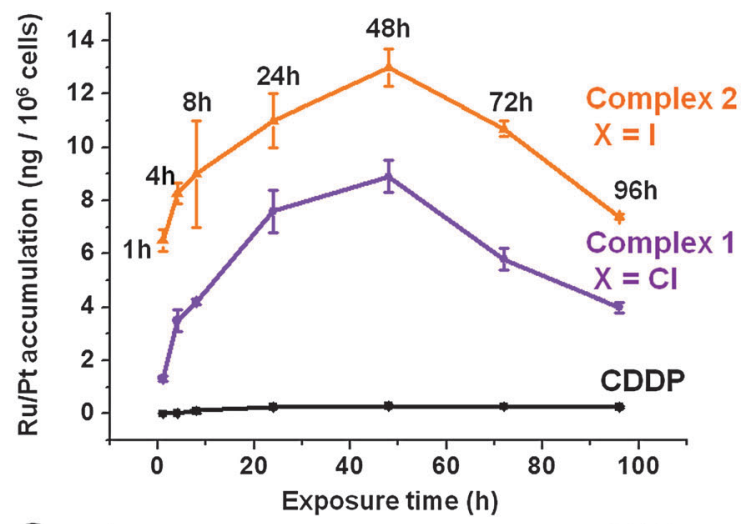

B
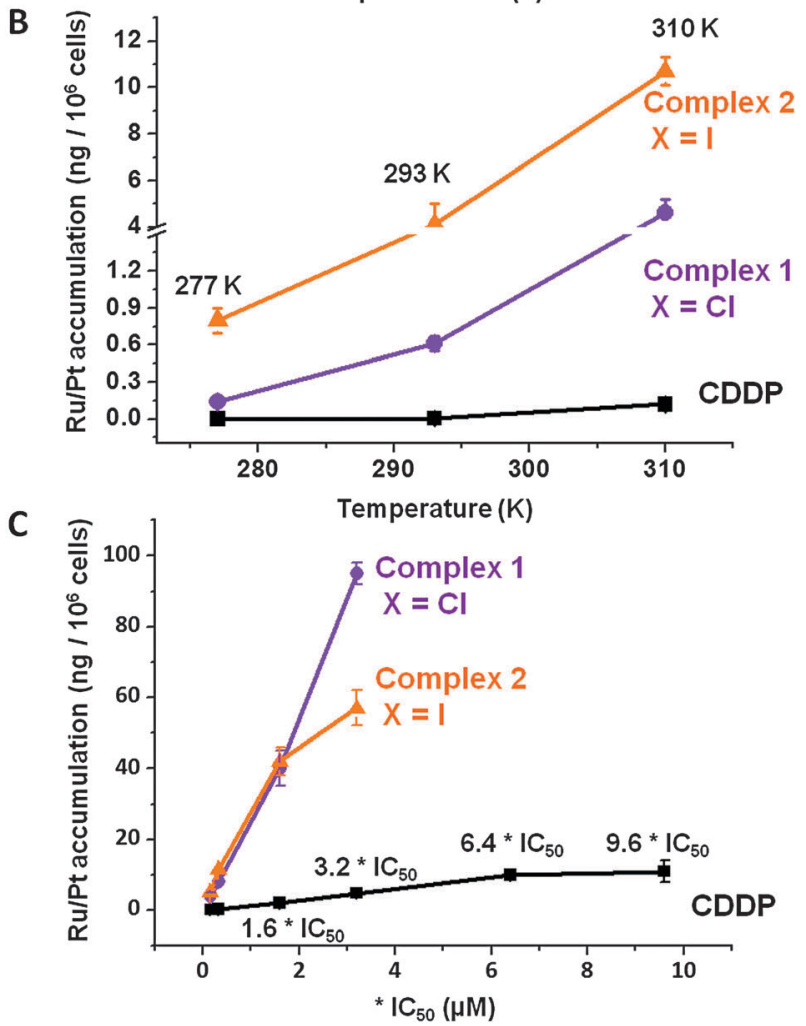

Fig. 2 (A) Time, (B) temperature, and (C) concentration dependence of $\mathrm{Ru} / \mathrm{Pt}$ accumulation in $\mathrm{A} 2780$ cells for complexes $\mathbf{1}\left(-\mathbf{-}_{-}\right), \mathbf{2}$ $\left(-\Delta_{-}\right)$and $\operatorname{CDDP}\left(-\mathbf{\square}_{-}\right)$at $310 \mathrm{~K}$. In all cases pre-incubation time before adding the drug was $24 \mathrm{~h}$ with no cell recovery time in drug-free medium, at $310 \mathrm{~K}$, in a $5 \% \mathrm{CO}_{2}$ humidified atmosphere.

from CDDP) is reached after $48 \mathrm{~h}$ of drug exposure, after which an influx/efflux equilibrium is reached (Fig. 2A and Table S2, ESI $\dagger$ ).

Temperature dependence. Cellular accumulation of $\mathrm{Ru}$ from complexes 1, 2 and Pt from CDDP (Fig. 2B and Table S3, ESI $\dagger$ ), was determined at three different temperatures. At $277 \mathrm{~K}$ there was no observable cellular accumulation of $\mathrm{Pt}$ from CDDP which indicates the active nature of its uptake. In contrast both $\mathrm{Ru}$ complexes were taken up even at this low temperature, which suggests that their uptake is partially passive and not energy-dependent, especially for iodido complex 2. The accumulation of $\mathrm{Ru}$ from both complexes increases with increasing temperature. 
Concentration dependence. The dose dependence of cellular accumulation of ruthenium for complexes $\mathbf{1}$ and $\mathbf{2}$ was determined in order to investigate whether saturation of the system is reached. These experiments were carried out using equipotent concentrations of each complex so that the data are comparable. Chlorido complex 1 does not seem to saturate the uptake pathway up to $50 \mu \mathrm{M}$ (Fig. $2 \mathrm{C}$ and Table S4, ESI $\dagger$ ). At higher concentrations (above $3.2 \times \mathrm{IC}_{50}$ values) both complexes cause total cell death. Cell uptake of Pt from CDDP does not saturate the system up to almost 10 times its $\mathrm{IC}_{50}$ value $(11.5 \mu \mathrm{M})$.

Extent of efflux. The total cellular accumulation of the metal depends both on cellular uptake and on the extent of efflux. Complexes $\mathbf{1}$ and $\mathbf{2}$ were used to investigate the extent of drug efflux with variable recovery times. These data are compared to the maximum cellular accumulation after $24 \mathrm{~h}$ exposure time studied earlier. Results indicate that even after $72 \mathrm{~h}$ in drug-free media, none of the complexes was completely excreted from the cell (Fig. 3 and Table S5, ESI $\uparrow$ ), being retained in both cases to more than $25 \%$ of the original uptake. Moreover, the extent of the efflux seems to reach a plateau after $48 \mathrm{~h}$.

Inhibition of efflux. In this study, A2780 cells were co-incubated with complexes $\mathbf{1}$ and $\mathbf{2}$ and verapamil. Their cellular accumulation was determined. In both cases ruthenium accumulation, after $24 \mathrm{~h}$ of recovery, increased with increasing verapamil concentration, (Fig. 3 and Table S6, ESI $\dagger$ ). Under normal conditions (recovery time in drug-free medium) iodido complex $\mathbf{2}$ undergoes a high extent of efflux during the first $24 \mathrm{~h}$, and $\mathrm{Ru}$ accumulation decreases by two thirds (from $11.5 \pm 0.8$ to $3.7 \pm 0.2 \mathrm{ng}$ of $\mathrm{Ru}$ per $10^{6}$ cells). At the highest concentration of verapamil used $(20 \mu \mathrm{M}), \mathrm{Ru}$ accumulation is reduced to only $7.2 \pm 0.2 \mathrm{ng}$ of $\mathrm{Ru}$ per $10^{6}$ cells.

Role of $\mathrm{Na}^{+} / \mathrm{K}^{+}$pump in cellular metal accumulation, as a facilitated diffusion endocytosis pathway. In order to investigate if membrane potential plays a role in the cellular accumulation of

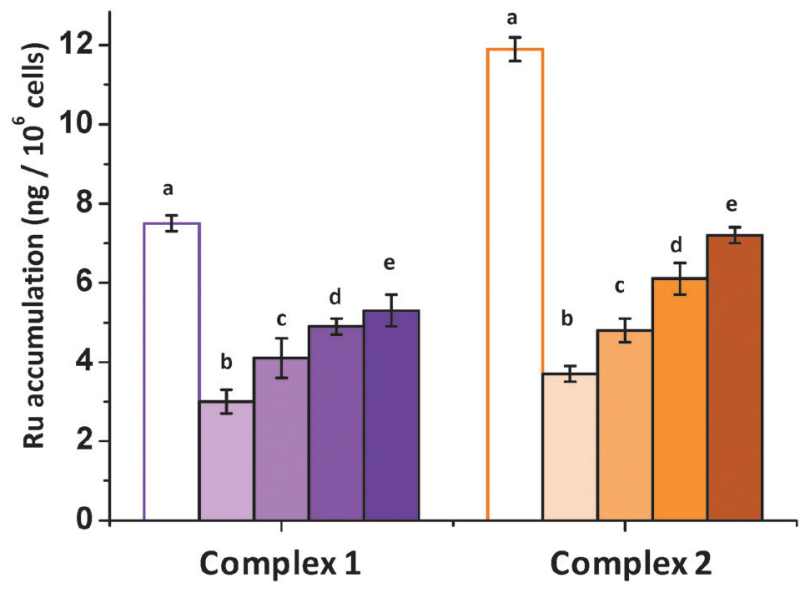

Fig. 3 Accumulation of $\mathrm{Ru} / \mathrm{Pt}$ in A2780 cells after co-incubation with complexes $\mathbf{1}(\mathbf{D}), \mathbf{2}(\square)$ and various concentrations of verapamil at $310 \mathrm{~K}$. Results are expressed as ng of metal per $10^{6}$ cells. Equipotent concentrations used were $\mathbf{1}=5 \mu \mathrm{M}$ and $\mathbf{2}=1 \mu \mathrm{M}$. For both complexes, (a) metal accumulation with no recovery time (full extent of efflux), (b) metal accumulation with $24 \mathrm{~h}$ recovery time and $0 \mu \mathrm{M}$ verapamil, (c) $5 \mu \mathrm{M}$, (d) $10 \mu \mathrm{M}$ and (e) $20 \mu \mathrm{M}$ of verapamil.
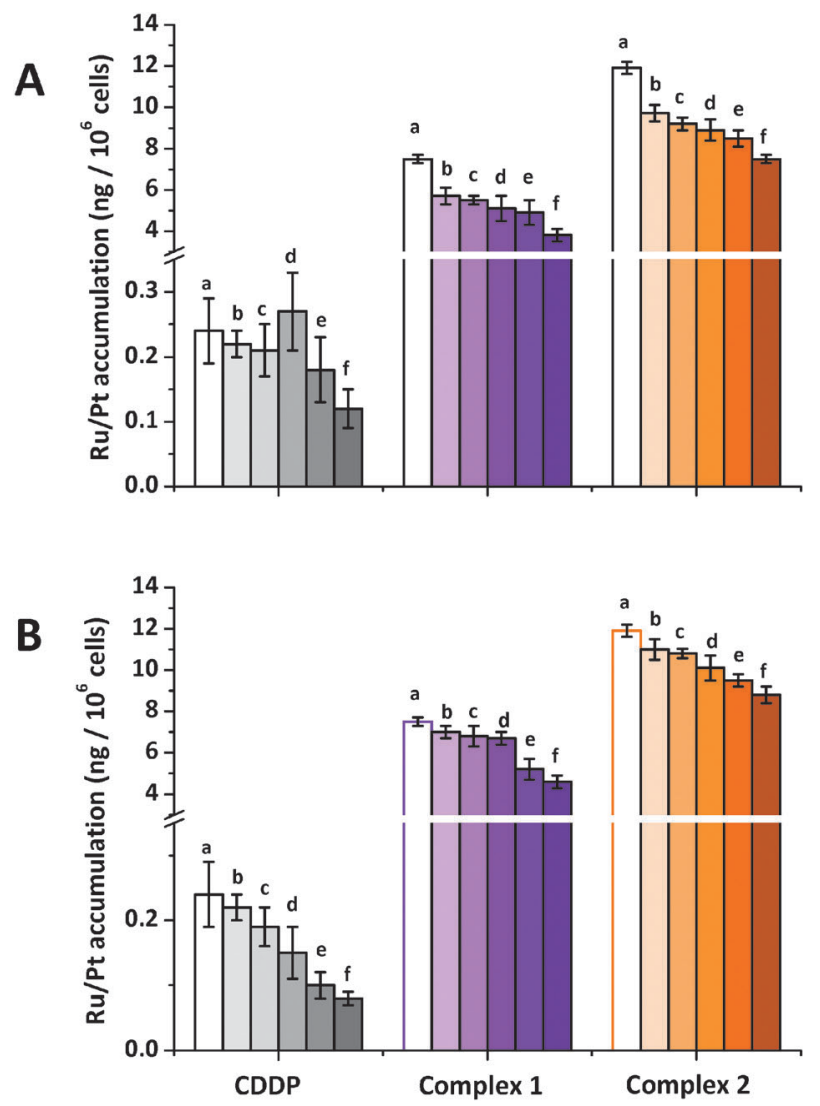

Fig. 4 Accumulation of $\mathrm{Ru} / \mathrm{Pt}$ in A2780 cells after co-incubation with CDDP $(\boldsymbol{\square})$, complexes $\mathbf{1}(\square)$ and $\mathbf{2}(\square)$ and various concentrations of (A) ouabain (a) $20 \mu \mathrm{M}$, (b) $5 \mu \mathrm{M}$, (c) $10 \mu \mathrm{M}$, (d) $20 \mu \mathrm{M}$, (e) $0.1 \mathrm{mM}$ and (f) $0.2 \mathrm{mM}$ (B) copper(II) (a) $0 \mu \mathrm{M}$, (b) $5 \mu \mathrm{M}$, (c) $10 \mu \mathrm{M}$, (d) $20 \mu \mathrm{M}$, (e) $0.1 \mathrm{mM}$ and (f) $0.2 \mathrm{mM}$. In all cases equipotent concentrations used were $\mathrm{CDDP}=0.4 \mu \mathrm{M}, \mathbf{1}=5 \mu \mathrm{M}$ and $\mathbf{2}=1 \mu \mathrm{M}$.

ruthenium, A2780 cells were incubated with complexes $\mathbf{1}, \mathbf{2}$ or CDDP and variable concentrations of ouabain $(5,10,20 \mu \mathrm{M}, 0.1$ or $0.2 \mathrm{mM}$ ). In all cases cellular metal accumulation decreases as ouabain concentration increases (Fig. 4A and Table S7, ESI $\dagger$ ). This was particularly evident in the case of CDDP, where Pt accumulation decreases to one half of its original value when co-incubated with $0.2 \mathrm{mM}$ of ouabain (to $0.12 \pm 0.03$ from $0.24 \pm 0.05 \mathrm{ng}$ of Pt per $10^{6}$ cells). The same is true for the accumulation of ruthenium from chlorido complex $\mathbf{1}$, which decreases from $7.5 \pm 0.2$ to $3.8 \pm$ $0.3 \mathrm{ng}$ of Ru per $10^{6}$ cells at similar ouabain concentration, and for complex $2 \mathrm{Ru}$ accumulation decreases from $11.9 \pm 0.8$ to $7.5 \pm$ $0.2 \mathrm{ng}$ of $\mathrm{Ru}$ per $10^{6}$ cells in the presence of $0.2 \mathrm{mM}$ of ouabain.

Role of CTR1 in cellular metal accumulation. A2780 cells were co-incubated with complexes $\mathbf{1}$ or $\mathbf{2}$ and variable amounts of copper(II) chloride $(10,20,40 \mu \mathrm{M}, 0.1$ or $0.2 \mathrm{mM})$ to study the effect of $\mathrm{Cu}$ on ruthenium accumulation, and therefore the involvement of the copper transporter CTR1 in the cellular uptake. CDDP was also studied for comparison. Results indicate that with $200 \mu \mathrm{M}$ of $\mathrm{Cu}^{\mathrm{II}}, \mathrm{Pt}$ accumulation from CDDP is reduced by $c a .40 \%$ (Fig. 4B and Table S8, ESI $\dagger$ ). At a concentration of $200 \mu \mathrm{M}$ of $\mathrm{Cu}^{\mathrm{II}}$, accumulation of $\mathrm{Ru}$ by A2780 cells from chlorido complex $\mathbf{1}$ is $26 \%$ less, while for iodido complex 2 , uptake is reduced to a third of its original value. 


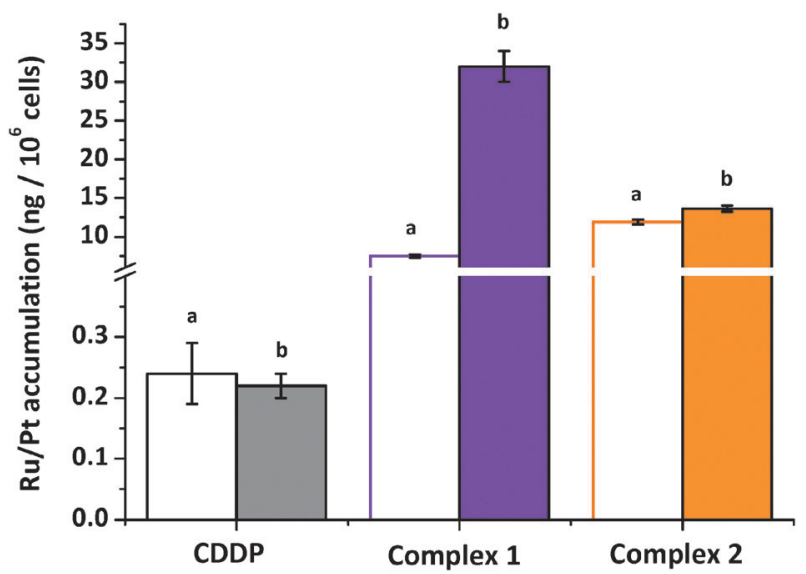

Fig. 5 Accumulation of $\mathrm{Ru} / \mathrm{Pt}$ in A2780 cells after co-incubation with CDDP ( $)$, complexes $1(\square), 2(\square)$ and antimycin at $310 \mathrm{~K}$. Results are expressed as ng of metal per $10^{6}$ cells. Equipotent concentrations used were $\mathrm{CDDP}=0.4 \mu \mathrm{M}, \mathbf{1}=5 \mu \mathrm{M}$ and $\mathbf{2}=1 \mu \mathrm{M}$. For all complexes the antimycin concentrations were (a) $0 \mu \mathrm{M}$, (b) $5 \mu \mathrm{M}$.

Role of ATP depletion in cellular metal accumulation. Antimycin $\mathrm{A}_{1}$, which can deplete ATP levels, ${ }^{23}$ was used as co-incubating agent with complexes 1, 2 and CDDP in order to investigate whether A2780 cellular accumulation is affected by changes of ATP concentration in the cell and compared to CDDP. Results suggest that accumulation of platinum from CDDP and Ru from iodido complex $\mathbf{2}$ are unaffected after changes in ATP levels (Fig. 5 and Table S9, ESI $\dagger$ ). However cellular accumulation of ruthenium from chlorido complex 1 increases markedly from $7.5 \pm 0.2$ to $32 \pm$ $2 \mathrm{ng}$ of Ru per $10^{6}$ cells when co-incubated with $5 \mu \mathrm{M}$ of antimycin.

Membrane disruption by amphotericin $B$ as a model for protein-mediated uptake. A2780 cells and complexes 1, 2 or CDDP were co-incubated with variable amounts of amphotericin $\mathrm{B}(1 \mu \mathrm{M}, 5 \mu \mathrm{M}, 10 \mu \mathrm{M}$ or $20 \mu \mathrm{M})$ to observe changes in their cellular accumulation due to the formation of pores in the cellular membrane caused by this antifungal drug. Fig. 6A shows that $\mathrm{Pt}$ accumulation from CDDP is doubled in the presence of $10 \mu \mathrm{M}$ amphotericin, a similar behaviour was observed for $\mathrm{Ru}$ accumulation from the iodido complex 2 (Table S10, ESI $\dagger$ ).

The role of the caveolae endocytosis pathway in metal accumulation. A2780 cells were co-incubated with complexes 1, 2 or CDDP and variable amounts of $\beta$-methyl cyclodextrin (10, $20 \mu \mathrm{M}, 0.5$ or $1 \mathrm{mM}$ ) and changes in metal accumulation determined. In all cases, the presence of $\beta$-methyl cyclodextrin caused no significant change in platinum or ruthenium accumulation in cells (Fig. 6B and Table S11, ESI $\dagger$ ).

\section{Discussion}

First it is important to consider the aqueous solution behavior of the chlorido complex $1[\mathrm{Ru}(p \text {-cym })(\operatorname{ImpyNMe} 2) \mathrm{Cl}]^{+}$and iodido complex $2[\mathrm{Ru}(p \text {-cym })(\operatorname{ImpyNMe} 2) \mathrm{I}]^{+}$. Our investigations by ${ }^{1} \mathrm{H}-\mathrm{NMR}$ (reported elsewhere), show that both complexes can undergo aquation; $2 \mathrm{mM}$ solutions generate $c a$. $64 \%$ of the aqua adduct after $24 \mathrm{~h}$ at $310 \mathrm{~K}$ (Table S1, ESI $\dagger$ ). ${ }^{21}$ However, surprisingly, we found that the iodido complex $\mathbf{2}$ does not
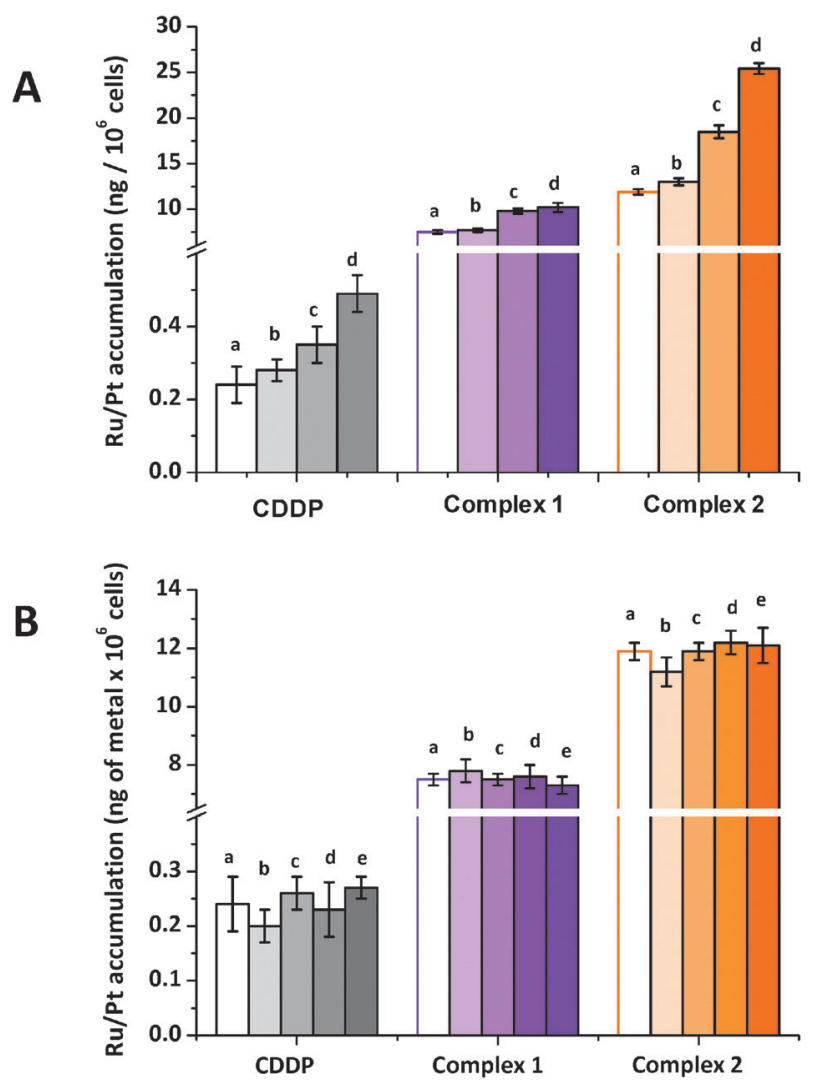

Fig. 6 Accumulation of $\mathrm{Ru} / \mathrm{Pt}$ in A2780 cells after co-incubation with CDDP $(\square)$, complexes $\mathbf{1}(\square), 2(\square)$ and various concentrations of (A) amphotericin B (a) $0 \mu \mathrm{M}$, (b) $1 \mu \mathrm{M}$, (c) $5 \mu \mathrm{M}$ and (d) $10 \mu \mathrm{M}$, or (B) $\beta$-methyl cyclodextrin (a) $0 \mu \mathrm{M}$, (b) $10 \mu \mathrm{M}$ (c) $20 \mu \mathrm{M}$, (d) $0.5 \mathrm{mM}$ and (e) $1 \mathrm{mM}$. All the experiments were carried out at $310 \mathrm{~K}$ in a $5 \%$ $\mathrm{CO}_{2}$ humidified atmosphere and the equipotent concentrations used were $\mathrm{CDDP}=0.4 \mu \mathrm{M}, \mathbf{1}=5 \mu \mathrm{M}$ and $\mathbf{2}=1 \mu \mathrm{M}$.

undergo conversion to its chlorido analogue in the presence of physiologically relevant $\mathrm{NaCl}$ concentrations and is stable up to $48 \mathrm{~h}$ in cell culture medium $(\mathrm{NaCl}$ concentration of $108 \mathrm{mM}){ }^{21}$ Hence the differences in biological behavior studied here can be reasonably attributed largely to differences in cell recognition and transport of the intact chlorido and iodido complexes. Indeed they exhibit marked differences in their antiproliferative activity. Complex $\mathbf{2}$ is $5 \times$ more potent than complex $\mathbf{1}$ in A2780 ovarian carcinoma; furthermore, its activity is of similar potency to cisplatin. If the iodido complex was converted into the chlorido complex, this would not be the case. We now discuss the differences in their cell uptake and accumulation pathways investigated in the present work which are likely to contribute greatly to the difference in their potency and mechanism of action. The main emphasis in the present work is on uptake pathways. Species formed by transformation of the complexes in the cytosol, by e.g. aquation and reaction with glutathione, may be involved in the efflux pathways but these are not considered in detail here.

\section{Pathways involved in cellular uptake and accumulation}

The extent of the $\mathrm{Ru}$ accumulation in A2780 ovarian cancer cells was determined using equipotent concentrations $\left(\mathrm{IC}_{50} / 3\right)$ 
of complexes 1, $\mathbf{2}$ and CDDP. Results in Table 1 indicate that the accumulation Ru from complexes $\mathbf{1}$ and $\mathbf{2}$ is more than one order of magnitude higher than Pt accumulated from CDDP, indicating that $\mathrm{Ru}$ accumulation pathways are more efficient than those involved in Pt uptake.

Mechanisms of Pt cellular uptake from cisplatin and cellular accumulation have been widely investigated, ${ }^{11,14}$ however little is known about the analogous pathways involved in the uptake of half-sandwich ruthenium anticancer complexes. ${ }^{24}$ One of the aims of this study was to gain a more in-depth understanding of this crucial step. It has been reported that CDDP uptake is linear during the first $60 \mathrm{~min}$ of drug exposure, ${ }^{25}$ however the present investigation involves a longer time frame. A2780 ovarian cells were exposed to complex 1, its iodido analogue complex 2 and CDDP over seven different periods of time ranging from 1 to $96 \mathrm{~h}$. In all cases, maximum cellular metal accumulation occurs between $24-48 \mathrm{~h}$ of drug exposure, after this time, the amount of accumulated $\mathrm{Pt} / \mathrm{Ru}$ decreases slightly. The accumulation of Pt from CDDP appears to reach a plateau after $96 \mathrm{~h}$ (Fig. 2A).

Active transport, as the movement of a substance across a cell membrane that involves energy consumption, is considered responsible for the uptake of numerous drugs. ${ }^{26,27}$ Therefore, the temperature dependence of the cellular uptake and accumulation of Ru was also investigated. Experiments were carried out at three different temperatures, $277 \mathrm{~K}, 295 \mathrm{~K}$ and $310 \mathrm{~K}$. CDDP influx does not occur at the lowest temperature $(277 \mathrm{~K})$, which is consistent with previous reports that CDDP uptake is energy-dependent. ${ }^{28}$ As expected for an energy-dependent process, CDDP influx begins at $295 \mathrm{~K}$ and increases as the temperature is raised to $310 \mathrm{~K}$ (from $0.005 \pm 0.002 \mathrm{ng}$ of $\mathrm{Pt}$ to $0.12 \pm 0.03 \mathrm{ng}$ of Pt per $10^{6}$ cells). The temperature dependence of $\mathrm{Ru}$ accumulation for complexes $\mathbf{1}$ and $\mathbf{2}$ is very different. Although an increased uptake accompanies an increase in temperature, only complex $\mathbf{2}$ exhibited energy-independent uptake at $277 \mathrm{~K}\left(0.8 \pm 0.1 \mathrm{ng}\right.$ of $\mathrm{Ru}$ per $10^{6}$ cells) (Fig. 2B). Another important factor investigated was the saturation of the cellular uptake with increasing drug concentration (Fig. 2C). Experiments were carried out at equipotent concentrations of complexes 1, 2 and CDDP. Platinum uptake slows down after reaching $6.4 \times \mathrm{IC}_{50}$ concentration values $(7.6 \mu \mathrm{M})$, but does not reach a plateau. This is consistent with previous reports indicating that CDDP accumulation does not saturate up to $100 \mu \mathrm{M}$ CDDP. ${ }^{17}$ Meanwhile, ruthenium complexes $\mathbf{1}$ and $\mathbf{2}$ exhibit a much sharper gradient; concentrations of up to $3.2 \times$ $\mathrm{IC}_{50}$ values do not cause saturation of the accumulation pathways. It is also relevant that at concentrations above $6.4 \times \mathrm{IC}_{50}$, total cell death was observed for both Ru complexes $\mathbf{1}$ and $\mathbf{2}$. Therefore the concentration of $\mathrm{Ru}$ at which saturation occurs could not be established.

Cellular accumulation of metal $(\mathrm{Ru} / \mathrm{Pt})$ arises as the result of two important processes: cellular influx and efflux. The latter is especially important in antiproliferative activity determinations that involve a cell recovery period in drug-free medium. The extent of the efflux of Ru for chlorido complex $\mathbf{1}$ and its iodido analogue $\mathbf{2}$ was investigated over time (Fig. 3). A2780 ovarian cells were exposed to the ruthenium complexes for $24 \mathrm{~h}$ and then left to recover for various periods of time. Although there is a significant efflux during the first $24 \mathrm{~h}$ of recovery, the concentration of metal retained in the cells reaches a plateau after $48 \mathrm{~h}$, with no marked difference between 24 and $48 \mathrm{~h}$. Notably, at the longest time point used, at least $25 \%$ of the original ruthenium is retained.

One of the most important mechanisms of resistance to anticancer pharmaceuticals involves impaired cellular accumulation as a result of an increased extent of efflux. ${ }^{29}$ Therefore investigating the mechanism of efflux of a drug can provide insights into the mechanism of resistance. Verapamil, an L-type calcium channel blocker, effectively abrogates P-gp mediated active efflux of anticancer drugs in ovarian cancer cells by competitive inhibition of drug transport, and is capable of reversing multi-drug resistance. ${ }^{30-32}$ Although it is not fully understood how verapamil interacts with P-gp to decrease cellular efflux, it has been reported that $50 \mu \mathrm{M}$ of verapamil is capable of restoring doxorubicin sensitivity in MDR cell lines ${ }^{30}$ by blocking active efflux. ${ }^{33}$ Accordingly, complexes $\mathbf{1}$ and $\mathbf{2}$ were used to investigate the extent of $\mathrm{Ru}$ efflux when cells are allowed to recover in drug-free medium that contains verapamil.

By increasing the concentration of verapamil it is possible to impair the efflux of ruthenium complexes 1 and 2 (Fig. 3). This is especially important for chlorido complex $\mathbf{1}$ which is retained by more than $70 \%$ in the presence of $20 \mu \mathrm{M}$ of this calcium channel blocker. This result is consistent with P-gp involvement in the efflux of complex $\mathbf{1}$. However, it is remarkable that preliminary molecular docking calculations ${ }^{34}$ carried out for the $\mathrm{N}, \mathrm{N}$-iminopyridine chelating ligand seem to indicate that this is not a P-gp substrate. The use of verapamil to restore the sensitivity of cancer cells to ruthenium arene complexes and involvement of P-gp in resistance has been demonstrated previously. ${ }^{6}$ In particular, sensitivity to $\left[\mathrm{Ru}\left(\eta_{6}-p\right.\right.$-bip)(en)Cl] $\mathrm{PF}_{6}$ (RM175), is restored by verapamil in adriamycin-resistant $\mathrm{A} 2780 \mathrm{AD}$ cells. ${ }^{30}$ In contrast, verapamil does not restore CDDP sensitivity, as the it is not recognized by P-gp. ${ }^{35-37}$

Polar molecules are not usually thought to diffuse freely through the cell membrane; instead, they need to rely on membrane proteins or membrane channels to reach the interior of cell compartments. One of these proteins in the plasma membrane is the sodium-potassium adenosine triphosphatase enzyme or $\mathrm{Na}^{+} / \mathrm{K}^{+}$pump which is responsible for maintaining cellular volume and, most importantly, for maintaining the resting potential of the cell. ${ }^{14,17,38,39}$ The function of this pump is altered by ouabain which reduces the sodium gradient across the cell membrane causing the membrane potential to change. ${ }^{40}$ There are no previous reports that investigate the effect of co-administering ouabain with ruthenium drugs. To analyse cellular accumulation of $\mathrm{Ru}$ under these conditions, A2780 cells were co-incubated with complexes 1, 2 and 5-200 $\mu \mathrm{M}$ of ouabain. Corresponding data for CDDP were also obtained (Fig. 4A). In the case of complexes 1 and 2, co-administration with the cardiac glycoside ouabain impaired cellular $\mathrm{Ru}$ accumulation. Ruthenium accumulation from complex $\mathbf{1}$ is almost halved from $7.5 \pm 0.2 \mathrm{ng}$ of $\mathrm{Ru}$ to $3.8 \pm 0.3 \mathrm{ng}$ of $\mathrm{Ru}$ per $10^{6}$ cells when co-administered with $200 \mu \mathrm{M}$ of ouabain. Similarly, for complex $\mathbf{2}, \mathrm{Ru}$ accumulation decreases by ca. $40 \%$ from $11.9 \pm 0.3 \mathrm{ng}$ of Ru to $7.2 \pm 0.2 \mathrm{ng}$ of $\mathrm{Ru}$ per $10^{6}$ cells when co-administered with the same concentration of ouabain. These results suggest that the cellular uptake of these 
ruthenium complexes relies at least in part on facilitated diffusion, and in particular is dependent on the membrane potential. As expected from previous reports, ${ }^{17,25}$ cisplatin accumulation is also reduced with increasing concentrations of ouabain, by about $50 \%$ from $0.24 \pm 0.05 \mathrm{ng}$ of Pt to $0.12 \pm$ $0.05 \mathrm{ng}$ of Pt per $10^{6}$ cells when co-administered with $200 \mu \mathrm{M}$ of the glycoside. Although the mechanism of inhibition is still not clear, it has been proposed that the sodium gradient in the membrane determines the facilitated transport of CDDP into the cells. ${ }^{14,41}$ This suggests that CDDP transport is dependent on the membrane potential, therefore any agent that affects the electrochemical gradient in the cell could potentially modify CDDP uptake. ${ }^{28}$ The decrease in CDDP cellular accumulation caused by the action of ouabain on the $\mathrm{Na}^{+} /$ $\mathrm{K}^{+}$-ATPase pump, ${ }^{11}$ is caused by changes in the electrochemical gradient and not because the pump itself transports the drug into the cell. ${ }^{28}$

Cellular accumulation of CDDP has been linked to copper transport pathways in mammalian cells. ${ }^{42,43}$ Hence, A2780 cells were co-incubated with complexes 1, 2 and various concentrations of $\mathrm{Cu}^{\mathrm{II}}$ with the aim of investigating whether CTR1 is also involved in the transport of these complexes across the cellular membrane. Corresponding data for CDDP were also obtained for comparison (Fig. 4B). Results suggest that the CTR 1 pathway may also be involved in the uptake of ruthenium complexes 1 and 2 . Fig. 4A shows that the accumulation of $\mathrm{Ru}$ from chlorido complex $\mathbf{1}$ decreases by $26 \%$ in the presence of the highest concentration of copper used $(0.2 \mathrm{mM})$. The results for complex $\mathbf{2}$ are more striking as $\mathrm{Ru}$ accumulation is lowered by $33 \%$ when co-administered with $200 \mu \mathrm{M}$ of $\mathrm{Cu}^{\text {II }}$ (from $11.9 \pm 0.3 \mathrm{ng}$ of $\mathrm{Ru}$ per $10^{6}$ cells to $8.8 \pm 0.4 \mathrm{ng}$ of $\mathrm{Ru}$ per $10^{6}$ ). A2780 ovarian cancer cells were also co-incubated with CDDP together with various concentrations of $\mathrm{Cu}^{\mathrm{II}}$ that ranged between $10 \mu \mathrm{M}$, and $0.2 \mathrm{mM}$. Under similar conditions Pt accumulation from CDDP was reduced by $c a$. $67 \%$, from $0.24 \pm 0.05 \mathrm{ng}$ of $\mathrm{Pt}$ to $0.08 \pm$ $0.01 \mathrm{ng}$ of Pt per $10^{6}$ cells in the presence of $0.2 \mathrm{mM} \mathrm{Cu}^{\mathrm{II}}$, a $40 \%$ reduction in accumulation of $\mathrm{Pt}$. These data are consistent with previous reports which indicate that CTR1 regulates CDDP toxicity by regulating CDDP uptake ${ }^{44}$ and that the expression of CTR1 alters sensitivity to CDDP and other platinum-containing anticancer drugs. ${ }^{45}$

Although the nature of the interaction of CDDP with CTR1, which facilitates Pt accumulation is poorly understood, recent NMR data show that CDDP binds to the methionine sulfur atoms on extracellular CTR1, to form monosulfur adducts $\left(\right.$ cis- $\left.\left[\mathrm{PtCl}(\mathrm{Met})\left(\mathrm{NH}_{3}\right)_{2}\right]^{+}\right)$that may facilitate the transport and activation of the drug. ${ }^{46}$ Such an interaction may also be involved in the activation and antiproliferative mechanism of other metal based-chemotherapeutic drugs such as ruthenium arene complexes since it is known that complexes such as $\left[\mathrm{Ru}\left(\eta_{6}-p\right.\right.$-bip)(en)Cl]PF $\mathrm{PF}_{6}$ (RM175) can form cysteine and methionine adducts. ${ }^{47}$

Some energy dependent pathways can be inhibited by lowering the levels of ATP. Such reduction of ATP concentrations can be achieved by co-administering antimycin A, a mitochondrial ATP synthesis inhibitor that interferes with oxidative phosphorylation by binding to the Qi site of cytochrome $c$ reductase. ${ }^{48-50}$ Antimycin $(1.5 \mu \mathrm{M})$ has been reported to achieve $90 \%$ depletion of ATP in LLC-PK cells (pig kidney cells) when exposed for $5 \mathrm{~h}^{48}$ In order to investigate the role of ATP depletion on cellular accumulation of $\mathrm{Ru}, \mathrm{A} 2780$ cells were co-incubated with complexes $\mathbf{1}$ or $\mathbf{2}$ and $5 \mu \mathrm{M}$ antimycin A. Similar experiments were also carried out using CDDP (Fig. 5).

It is expected that if the cellular uptake of complexes $\mathbf{1}$ and $\mathbf{2}$ is ATP-dependent, its depletion should cause a decrease in $\mathrm{Ru}$ cellular accumulation. However, only a small, non-significant variation was observed in the cellular accumulation of $\mathrm{Ru}$ from complex $2\left[\mathrm{Ru}\left(\eta^{6}-p\right.\right.$-cym $)(p$-Impy-NMe 2$\left.) \mathrm{I}\right] \mathrm{PF}_{6}$ (Fig. 5). These results suggest that $\mathrm{Ru}$ accumulation from $\mathbf{2}$ is largely ATP-independent. This is consistent with the significant cellular accumulation observed at low temperatures $(277 \mathrm{~K}$, vide supra). In contrast, Fig. 4 also shows that there is a major increase in cellular accumulation of ruthenium from complex $\mathbf{1}$ $\left[\mathrm{Ru}\left(\eta^{6}-p\right.\right.$-cym $\left.)\left(p-\operatorname{Impy}-\mathrm{NMe}_{2}\right) \mathrm{Cl}\right] \mathrm{PF}_{6}$. This behaviour may be due to the involvement of an ATP-dependent efflux pump in the detoxification of this complex. This could be an ABC transporter, such as the MRP2 pump. The MRP2 pump is inhibited by antimicin-induced ATP depletion; therefore its inhibition could allow intracellular $\mathrm{Ru}$ concentrations to increase. The ATP-dependent pump has been reported to be involved in the efflux of CDDP conjugated to glutathione and to multidrug resistance mechanisms. ${ }^{51}$

Fig. 5 also shows that co-incubation of A2780 cells with CDDP and $5 \mu \mathrm{M}$ of antimycin $\mathrm{A}$ does not reduce $\mathrm{Pt}$ accumulation significantly (from $0.24 \pm 0.05 \mathrm{ng}$ of Pt per $10^{6}$ cells to $0.22 \pm$ $0.02 \mathrm{ng}$ of $\mathrm{Pt}$ per $10^{6}$ cells). Even more striking is the report that carboplatin accumulation is inhibited by $90 \%$ in the BEL-7404 cell line treated with $50 \mu \mathrm{g} \mathrm{mL}^{-1}$ of antimycin $\mathrm{A}^{23}$

Enhanced protein-mediated transport across cell membranes has been reported as a means of increasing cellular accumulation. ${ }^{52}$ Consequently, the role of protein-mediated transport in the cellular accumulation of $\mathrm{Pt}$ and $\mathrm{Ru}$ drugs was investigated. A2780 cells were co-incubated with complexes 1, 2 or CDDP and variable concentrations of amphotericin $\mathrm{B}$, which forms pores in the cellular membrane. ${ }^{36,53-55}$

These pores, permeable to water and non-electrolytes, may give rise to increased drug influx and therefore higher cellular accumulation. Experimental results from co-incubation with amphotericin B (Fig. 6A) show that there is no significant variation in the cellular accumulation of $\mathrm{Ru}$ from complex $\mathbf{1}$, suggesting that facilitated diffusion is not involved in the uptake pathway of this complex. In contrast, cellular accumulation of Ru from complex 2 is doubled from $11.9 \pm 0.3 \mathrm{ng}$ of $\mathrm{Ru}$ per $10^{6}$ cells to $25.4 \pm 0.6 \mathrm{ng}$ of Ru per $10^{6}$ cells by the use of $10 \mu \mathrm{M}$ of amphotericin B. This result is consistent with the results of the temperature-dependent uptake studies (vide supra) that passive diffusion of this complex through the cell membrane is involved.

Fig. 6A also shows that co-incubation with amphotericin $\mathrm{B}$ causes Pt accumulation from CDDP to double, from $0.24 \pm$ $0.05 \mathrm{ng}$ to $0.49 \pm 0.05 \mathrm{ng}$ of Pt per $10^{6}$ cells. This is consistent with previous reports that amphotericin $\mathrm{B}$ increases CDDP cellular accumulation. ${ }^{14,36}$ This effect of amphotericin $\mathrm{B}$ on CDDP accumulation has been used to reverse Pt resistance in non-small cell lung cancer cells. ${ }^{17}$ However, when CDDP resistance develops, cells may also develop resistance to amphotericin B, 5-fluorouracil and aphidicolin. ${ }^{56}$ 
Finally, the role of the caveolae endocytosis pathway in cellular metal accumulation was explored (Fig. 6B). A2780 cells were co-incubated with complexes 1, 2 or CDDP and increasing concentrations of $\beta$-methyl cyclodextrin, a cholesterolextracting agent which disrupts caveolae. ${ }^{57,58}$ Results in Fig. 6B, indicate that this endocytosis pathway is not involved either in the uptake of Pt from CDDP nor in the uptake of Ru for complexes $\mathbf{1}$, $\mathbf{2}$ as there are no significant changes in cellular metal concentrations with increasing concentrations of $\beta$-methyl cyclodextrin.

\section{Conclusions}

Possible pathways for the uptake of the organometallic ruthenium arene anticancer complexes $1\left[\mathrm{Ru}\left(\eta^{6}-p\right.\right.$-cym $)\left(p\right.$-Impy-NMe $\left.{ }_{2}\right)$ -

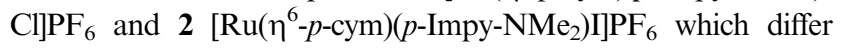
only in the monodentate halido ligand, have been investigated for A2780 ovarian cancer cells and compared to the clinical platinum drug CDDP. It was demonstrated that maximum $\mathrm{Ru}$ accumulation from both $\mathrm{Ru}$ complexes occurs between $24 \mathrm{~h}$ and $48 \mathrm{~h}$ of exposure. Also, complex 2 exhibits partial energyindependent uptake. In contrast CDDP is not taken up at low temperatures $(277 \mathrm{~K})$, and its accumulation is greatly enhanced by amphotericin $\mathrm{B}$, a facilitative diffusion agent. Cellular accumulation of ruthenium in A2780 cells was enhanced by inhibition of efflux pathways by verapamil, suggesting that a MDR protein, such as P-gp, could be involved in ruthenium efflux and detoxification. This is also supported by results of co-incubation with antimycin A, which show enhanced accumulation of chlorido complex $\mathbf{1}$ consistent with inhibition of the MRP2 pump which is ATP-dependent. Changes in the resting membrane potential induced by ouabain were shown to reduce $\mathrm{Ru}$ accumulation in A2780 ovarian cancer cells, which suggests that electrochemical gradients can modulate uptake. The CTR1 copper transporter, which is involved in the cellular uptake of CDDP, is likely to be involved as well in the uptake of iodido complex 2 . Finally it was shown that the caveolae endocytosis pathway is not involved in the uptake of either of the ruthenium complexes 1 or 2.

Although these $\mathrm{Ru}$ complexes exhibit very similar aqueous reactivity characteristics, achieving similar extents of hydrolysis after a $24 \mathrm{~h}$ period $(63-66 \%)$, we have shown that both complexes are stable in cell culture medium and that they do not undergo aquation in the presence of high $\mathrm{NaCl}$ concentrations. ${ }^{21}$ Therefore, the differences observed in their uptake pathways are likely to be related to the properties of the halido structures themselves, and not to the common aqua adduct. DFT calculations show that the iodido face of the pseudooctahedral half sandwich complex $\mathbf{2}$ is more positively-charged than for the chlorido complex $1 .{ }^{21}$ This change in polarization may play a major role in the remarkable difference in uptake.

Efflux of the complexes is likely to be affected by possible chemical transformations inside the cells. For example, reactions with glutathione may lead to thiolate as well as sulfenate and sulfinate derivatives, ${ }^{59,60}$ which may be recognized by efflux transporters, as in the case of products from reaction of CDDP with GSH. ${ }^{61,62}$ Hence aqua, GSH and complexes with other intracellular biomolecules may play a role in efflux, and will be interesting to investigate in future work.

\section{Acknowledgements}

We thank Dr Michael Khan for assistance with cell culture. Ms Ruth McQuitty for assistance with HPLC and members of COST Actions D39 and CM1105 for stimulating discussions. This research was supported by the ERC (grant no. 24363), AWM/ERDF, University of Los Andes, Venezuela (studentship for IR) and IAS University of Warwick, UK.

\section{References}

1 A. Casini, C. G. Hartinger, A. A. Nazarov and P. J. Dyson, Top. Organomet. Chem., 2010, 32, 57-80.

2 P. J. Dyson and G. Sava, Dalton Trans., 2006, 1929-1933.

3 A. Peacock and P. J. Sadler, Chem--Asian J., 2008, 3, 1890-1899.

4 G. Gasser, I. Ott and N. Metzler-Nolte, J. Med. Chem., 2011, 54, 3-25.

5 L. Ronconi and P. J. Sadler, Coord. Chem. Rev., 2007, 251, $1633-1648$.

6 Y. K. Yan, M. Melchart, A. Habtemariam and P. J. Sadler, Chem. Commun., 2005, 4764-4776.

7 J. Reedijk, Macromol. Symp., 2008, 270, 193-201.

8 P. C. Bruijnincx and P. J. Sadler, Curr. Opin. Chem. Biol., 2008, 12, 197-206

9 C. G. Hartinger, A. D. Phillips and A. Nazarov, Curr. Top. Med. Chem., 2011, 11, 2688-2702.

10 H. Timmer-Bosscha, N. H. Mulder and E. G. de Vries, Br. J. Cancer, 1992, 66, 227-238.

11 M. Kartalou and J. M. Essigmann, Mutat. Res., 2001, 478, 23-43.

12 M. Jones, J. Siracky, L. R. Kelland and K. R. Harrap, Br. J. Cancer, 1993, 67, 24-29.

13 D. Trachootham, W. Zhang and P. Huang, Oxidative stress and drug resistance in cancer, Springer US, New York, NY, 2009.

14 M. D. Hall, M. Okabe, D. W. Shen, X. Liang and M. M. Gottesman, Annu. Rev. Pharmacol. Toxicol., 2008, 48, 495-535.

15 A. M. Florea and D. Büsselberg, Cancer, 2011, 3, 1351-1371.

16 S. Ishida, J. Lee, D. J. Thiele and I. Herskowitz, Proc. Natl. Acad. Sci. U. S. A., 2002, 99, 14298-14302.

17 D. P. Gately and S. B. Howell, Br. J. Cancer, 1993, 67, 1171-1176.

18 D. Sinani, D. J. Adle, H. Kim and J. Lee, J. Biol. Chem., 2007, 282, 26775-26785.

19 M. Bennett and A. K. Smith, Dalton Trans., 1974, 233-241.

20 E. S. Sk, R. A. Zelonka and M. C. Baird, J. Organomet. Chem., 1972, 35, 43-46.

21 I. Romero-Canelón, L. Salassa and P. J. Sadler, Submitted.

22 P. Skehan, R. Storeng, D. Scudiero, A. Monks, J. McMahon, D. Vistica, J. T. Warren, H. Bokesch, S. Kenney and M. R. Boyd, J. Natl. Cancer Inst., 1990, 82, 1107-1112.

23 D. W. Shen, S. Goldenberg and I. R. A. Pastan, J. Cell. Physiol., 2000, 116, 108-116.

24 M. Groessl, O. Zava and P. J. Dyson, Metallomics, 2011, 3, 591-599.

25 V. Cepeda, M. Fuertes, J. Castilla, C. Alonso, C. Quevedo and J. M. Pérez, Anti-Cancer Agents Med. Chem., 2007, 7, 3-18.

26 J. Thomas, L. Wang, R. E. Clark and M. Pirmohamed, Blood, 2004, 104, 3739-3745.

27 P. D. Dobson and D. B. Kell, Nat. Rev. Drug Discovery, 2008, 7, 205-220.

28 P. A. Andrews, S. Velury, S. C. Mann and B. I. Stephen, Cancer Res., 1988, 48, 68-73.

29 M. M. Gottesman, S. V. Ambudkar and D. Xia, Nat. Biotechnol., 2009, 27, 546-547.

30 R. E. Aird, J. Cummings, A. A. Ritchie, M. Muir, R. E. Morris, H. Chen, P. J. Sadler and D. I. Jodrell, Br. J. Cancer, 2002, 86, $1652-1657$.

31 S. G. Aller, J. Yu, A. Ward, Y. Weng, S. Chittaboina, P. M. Harrell, Y. T. Trinh, Q. Zhang, I. L. Urbatsch and G. Chang, Science, 2009, 323, 1718-1722.

32 J. Ford and W. Hait, Pharmacol. Rev., 1990, 42, 155-199.

33 J. Cummings, J. S. Macpherson, I. Meikle and J. F. Smyth, Biochem. Pharmacol., 1996, 52, 979-990. 
34 Z. Bikadi, I. Hazai, D. Malik, K. Jemnitz, Z. Veres, P. Hari, Z. Ni, T. W. Loo, D. M. Clarke, E. Hazai and Q. Mao, PLoS One, 2011, 6, e25815.

35 J. D. Allen, R. F. Brinkhuis, L. V. Deemter, J. Wijnholds and A. H. Schinkel, Cancer Res., 2000, 60, 5761-5766.

36 S. Y. Sharp, P. Mistry, M. R. Valenti, P. Bryant and L. R. Kelland, Cancer Chemother Pharmacol., 1994, 35, 137-143.

37 L. Gibalová, M. Sereš, A. Rusnák, P. Ditte, M. Labudová, B. Uhrík, J. Pastorek, J. Sedlák, A. Breier and Z. Sulová, Toxicol. in Vitro, 2012, 26, 435-444.

38 J. Q. Chen, R. G. Contreras, R. Wang, S. V. Fernandez, L. Shoshani, I. H. Russo, M. Cereijido and J. Russo, Breast Cancer Res. Treat., 2006, 96, 1-15.

39 W. Zhang, H. Takeuchi, M. Kurono and M. Emaduddin, Gen. Pharmacol., 1997, 29, 625-632.

40 N. Ramu and R. Gorodetsky, Biochem. Pharmacol., 1991, 42, 1699-1704.

41 J. Uozumi and C. L. Litterst, Cancer Chemother Pharmacol., 1995, $15,93-96$

42 J. Lee, M. J. Petris and D. J. Thiele, J. Biol. Chem., 2002, 277, 40253-40259.

43 A. K. Holzer, K. Katano, L. W. J. Klomp and S. B. Howell, Clin. Cancer Res., 2004, 10, 6744-6749.

44 A. K. Holzer, G. H. Manorek and S. B. Howell, Mol. Pharmacol., 2006, 70, 1390-1394.

45 U. N. Kommuguri, S. Bodiga, S. Sankuru and V. L. Bodiga, J. Trace Elem. Med Biol., 2012, 26, 13-19.

46 X. Wang, X. Du, H. Li, D. S. B. Chan and H. Sun, Angew. Chem. Int. Ed., 2011, 50, 2706-2711.

47 F. Wang, H. Chen, J. Parkinson, P. D. S. Murdoch and P. J. Sadler, Inorg. Chem., 2002, 41, 4509-4523.
48 M. Venkatachalam, Y. Patel, J. Kreisberg and J. Weingberg, J. Clin. Invest., 1988, 81, 745-758.

49 J. Wilson, M. Winter and D. M. Shasby, Blood, 1990, 76, 2578-2582.

50 S. J. Atkinson, M. Hosford and B. Molitoris, J. Biol. Chem., 2004, 279, 5194-5199.

51 K. Taniguchi, M. Wada, K. Kohno and M. Kawakami, Cancer Res., 1996, 56, 4124-4129.

52 H. Resat and M. Baginski, Eur. Biophys. J., 2002, 31, 294-305.

53 B. Venegas, J. González-Damián, H. Celis and I. Ortega-Blake, Biophys. J., 2003, 85, 2323-2332.

54 G. Fujii, J. E. Chang, T. Coley and B. Steere, Biochemistry, 1997, 36, 4959-4968.

55 E. Romero, E. Valdivieso and B. E. Cohen, J. Membr. Biol., 2009, 230, 69-81.

56 T. Tanaka, H. Kurokawa, K. Matsuno, S. Matsumoto and Y. Hayashida, Anticancer Res., 2008, 28, 2663-2668.

57 D. Garmann, A. Warnecke, G. V. Kalayda, F. Kratz and U. Jaehde, J. Controlled Release, 2008, 131, 100-106.

58 R. Yumoto, H. Nishikawa, M. Okamoto, H. Katayama, J. Nagai and M. Takano, Am. J. Physiol-Lung C., 2006, 290, L946-L955.

59 F. Wang, J. Xu, A. Habtemariam, J. Bella and P. J. Sadler, J. Am. Chem. Soc., 2005, 127, 17734-17743.

60 F. Wang, S. Weidt, J. Xu, C. L. Mackay, P. R. R. LangridgeSmith and P. J. Sadler, J. Am. Soc. Mass Spectrom., 2008, 19 , 544-549.

61 X. Y. Hao, J. Bergh, O. Brodin, U. Hellman and B. Mannervik, Carcinogenesis, 1994, 15, 1167-1173.

62 H. H. W. Chen and M. T. Kuo, Met.-Based Drugs, 2010, 2010, pii:430939. 